\title{
Analysis on Solar Streetlights Battery Box Drop
}

\author{
Zecheng Zhuang ${ }^{1}$, Yinjing Yao ${ }^{1 *}$, Xueke Zhang ${ }^{1}$, Shichao Xu ${ }^{1}$, Junwang Hu ${ }^{1}$, Minhua Lan ${ }^{1}$, Tao Luo ${ }^{1}$ \\ ${ }^{1}$ School of Vocational and Technical Education, GuangXi Normal University of Science and Technology, LaiBin GuangXi, \\ 546199, China
}

\begin{abstract}
Solar streetlights are new type of road lighting lamps, and are used on islands, rural, industries, parks, schools and other public places. In consideration of which it was easy to drop and to damage in response to wind vibration and transportation. Thus, in this paper, the drop positions of new power solar lamp battery box were computed and force positions of battery box drop were analyzed by ABAQUS numerical simulation.
\end{abstract}

\section{Introduction}

Solar and wind are two types of clean energy sources which are widely used on resources technology, especially for solar energy, which are heavily invested by many countries. Solar energy is one of the cleanest energy resources whose development potential is enormous, and plays an important role in future energy development strategies [1]. It is easy to drop and damage in response to wind vibration or during carrying. Thus, ABAQUS was used to simulate the drop positions and force situations of new power solar lamp battery box.

Tannous et al. used life cycle assessment method( LCA), two street lighting technologies in Lebanon, traditional grid-connected and solar independent systems, were assessed and compared from the perspective of environment. It was found that solar systems have much less impact on overall environment when the landfill and recycling were considered[2]. Renato et al. took many vertical axis wind turbines into the lamppost structures, the PV panels were jointed, and energy was ensured by storage devices and power conversion devices that lighting is available during nighttime without wind, meanwhile, specialized safety equipment in extreme wind conditions was designed, and it can be automatically stopped to prevent turbine overspeeding[3]. Shi X X et al. applied wireless senor networks to wind-sight complementary street lamps, the
ZigBee technology was used on street lamps to communicate and monitor wind-sight complementary street lamps[4]. Shruti et al. designed a new type of solar energy LED street lamps which has an energy management algorithm and can automatically estimate solar energy stored in cells. Meanwhile, the whole system energy utilization was improved[5]. Li Y X, Yang Q S, et al. derived the background response equivalent static wind load of large-span buildings based on the equivalent strain energy, the problems were solved, which multiple structural response control objects should be considered when the equivalent static wind load of large-span buildings were computed[6]. Yan J et al. researched on the disk solar thermal power system frame structures, and a finite element modeling method on complex frame structures was proposed[7]. Bin et al. studied on 1.5 MW wind turbine tower tube. Linear filtering method was used to simulate the instantaneous wind speed under storm conditions, and the instantaneous wind speed was simulated to analyze the wind-induced response of fan tower[8]. Chen B et al. used numerical simulation to study transient dynamic response of CFRP cable under strong wind based on fluid-solid coupling theory[9].

\section{Numerical Simulation}

The material of battery box is Acrylonitrile- ButadienceStyrene, (ABS), material properties are as shown in Table 1.

Table 1. Material properties

\begin{tabular}{lcccc}
\hline & $\begin{array}{c}\text { Elasticity Modulus } \\
/ \mathrm{E}(\mathrm{MPa})\end{array}$ & $\begin{array}{c}\text { Poisson Ratio } \\
/ \mathrm{v}\end{array}$ & $\begin{array}{c}\text { Density } \\
/ \rho\left(\mathrm{kg} / \mathrm{m}^{3}\right)\end{array}$ & $\begin{array}{c}\text { Yield Strength } \\
/ \sigma_{\mathrm{s}}(\mathrm{MPa})\end{array}$ \\
\hline 1. ABS & 2.2000 & 3.0 .394 & 4.1020 & 5.50 \\
\hline
\end{tabular}

C3D8 linear hexahedron element and C3D4 linear tetrahedron element were used in calculation model. As drop collision is a transient dynamic change, the state of the product greatly changed in a short time, thus,
ABAQUS dominant nonlinear dynamic analysis solver, Dynamic and Explicit, were used to analyze the transient dynamic of battery box. Speed load method was used to apply load, this model was simulated which dropped from 
the height of $1.2 \mathrm{~m}$ and $1.5 \mathrm{~m}$, the impact surface was assumed to be rigid. The drop displacement and impact velocity were as shown in Equation(1) and Equation(2)[9, $10]$.

$$
\begin{aligned}
& x=\frac{1}{2} g t^{2} \\
& v=g t
\end{aligned}
$$

where gravity acceleration g equals to $9.8 \mathrm{~kg} / \mathrm{m}^{3}$

The standard drop situations can be divided into surface drop, edge drop and corner drop, thus, in order to

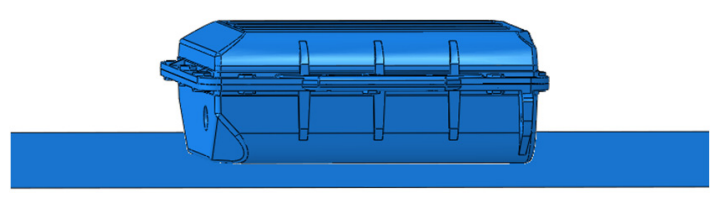

Fig1. Bottom surface drop model

\subsection{Edge Drop}

The battery box drop was regarded as free fall, and the edge hit the ground which was taken as rigid. Battery box

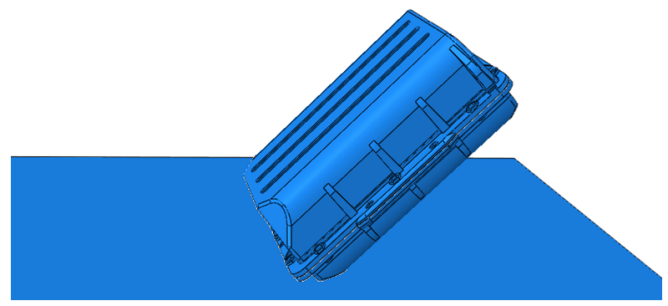

Fig3. Side edge drop model

\subsection{Corner Drop}

The battery box drop was regarded as free fall, the corner impacted on the ground which was taken as rigid. Battery box flanked to ground with $45^{\circ}$ inclination angle, the drop heights were set to $1.2 \mathrm{~m}$ and $1.5 \mathrm{~m}$, the drop model were shown in Figure 4.

\section{Results and discussions}

Table 2. Maximum Mises stress on different drop positions

\begin{tabular}{ccccc}
$\begin{array}{c}\text { 6. Mises } \\
\text { Stress/MPa }\end{array}$ & $\begin{array}{c}\text { 7. Bottom } \\
\text { Drop }\end{array}$ & $\begin{array}{c}\text { 8. Side } \\
\text { Drop }\end{array}$ & $\begin{array}{c}\text { 9. Edge } \\
\text { Drop }\end{array}$ & $\begin{array}{c}\text { 10. Corner } \\
\text { Drop }\end{array}$ \\
\hline 11.1 .2 & 12.16 & 13.44 & 14.71 & 15.76 \\
16.1 .5 & 17.18 & 18.49 & 19.79 & 20.87 \\
\hline
\end{tabular}

analyze the actual drop of the battery box during handling, three different kinds of drop situations were simulated after battery boxes hit the ground.

\subsection{Surface Drop}

The battery box drop was regarded as free fall, and hit the ground which was taken as rigid. The whole battery box fall vertically without inclination angle, and the drop heights were set to $1.2 \mathrm{~m}$ and $1.5 \mathrm{~m}$, the drop model were shown in Figure 1.and Figure 2.

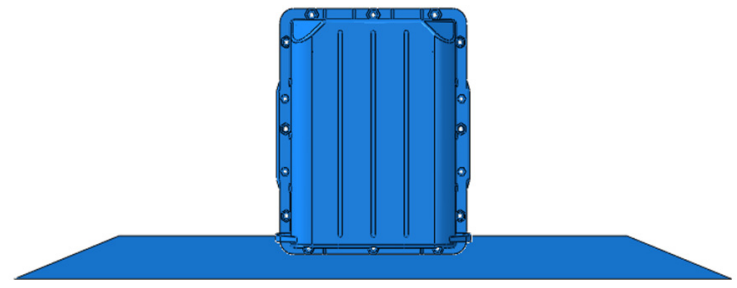

Fig2. Side surface drop model

flanked to ground with $45^{\circ}$ inclination angle, the drop heights were set to $1.2 \mathrm{~m}$ and $1.5 \mathrm{~m}$, the drop model were shown in Figure 3.

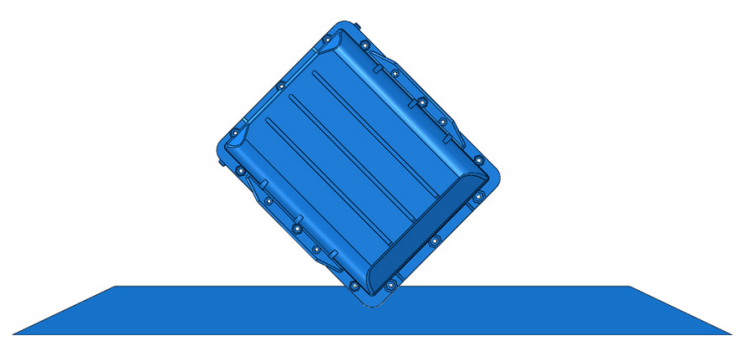

Fig4. Corner drop model

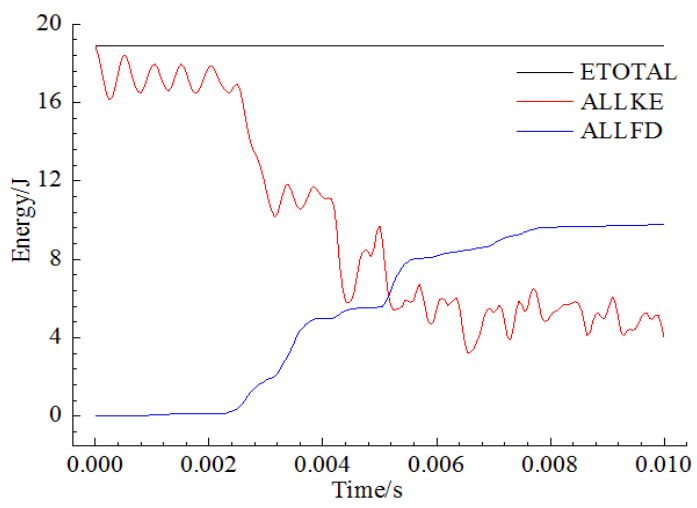

Fig5. Energy changes of system in drop Different drop positions were shown in Table 2, the max Mises stress of battery box. It was found that the stress effect of corner drop was biggest, next was edge drop, however, the surface drop is safe due to large contact area.

As shown in Figure 5. the total system energy (ETOTAL) held the line, but the total kinetic energy (ALLKE) dropped off and the friction dissipative energy 
(ALLFD) gradually increased when battery box hit the ground,and finally tend to stable.

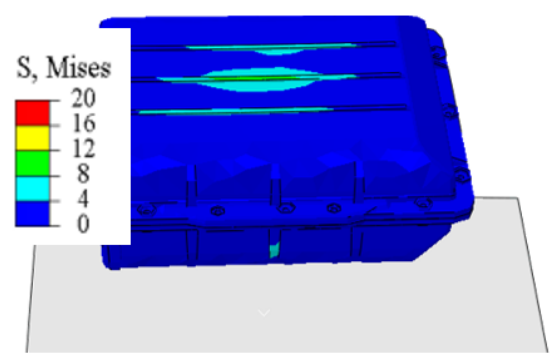

(a) $1.2 \mathrm{~m}$

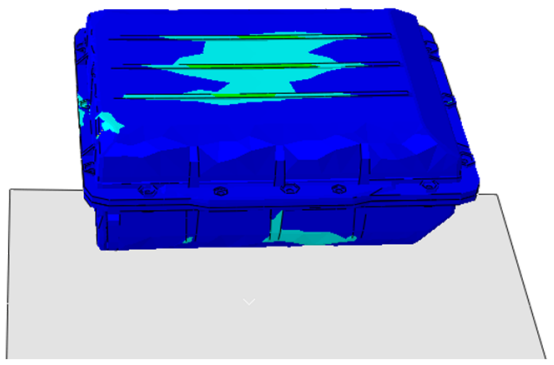

(b) $1.5 \mathrm{~m}$

Fig6. Bottom drop of battery box stress cloud map

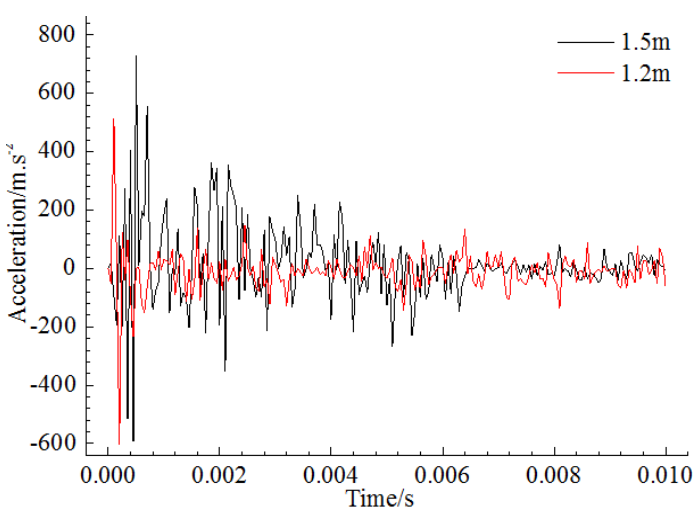

Fig7. Figure 7. Acceleration curve on the center of bottom

The stress cloud map of battery box are as shown in Figure 6, it can be found that the bottom surface had local stress concentration, but the value of stress is small, the max Mises stress is only $18 \mathrm{MPa}$, though it was fall from the height of $1.5 \mathrm{~m}$. Acceleration curve on the center of the bottom during drop were shown in Figure 7, and it was found that the acceleration increased rapidly and then

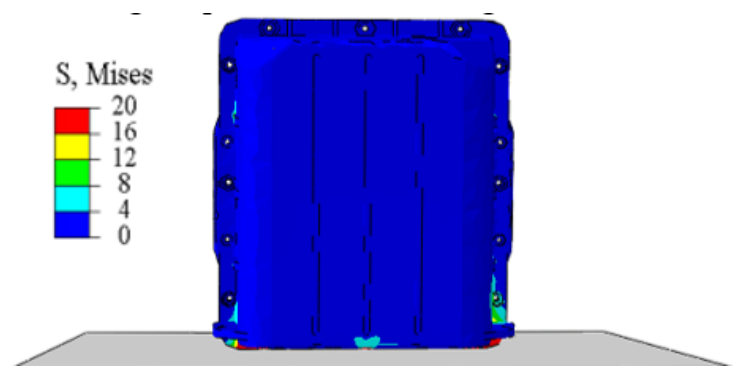

(a) $1.2 \mathrm{~m}$

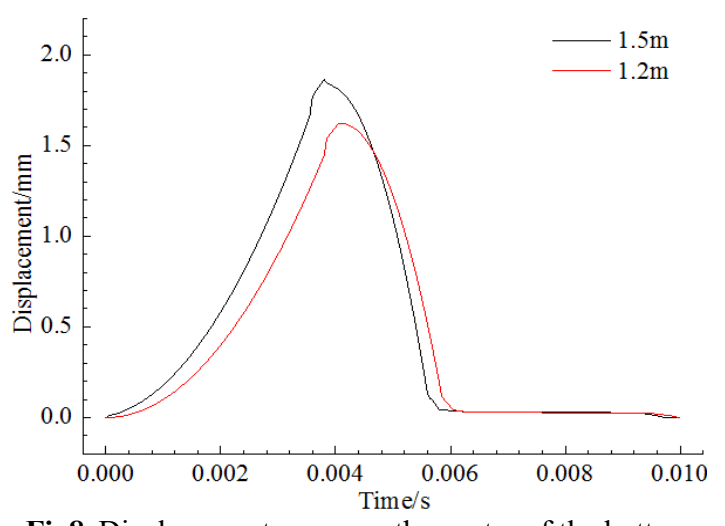

Fig8. Displacement curve on the center of the bottom

decreased to zero. Displacement curve at the center of the bottom surface during drop were as shown in Figure 8, and it was found that the battery box bounced up after landing, then fell, and finally landed.

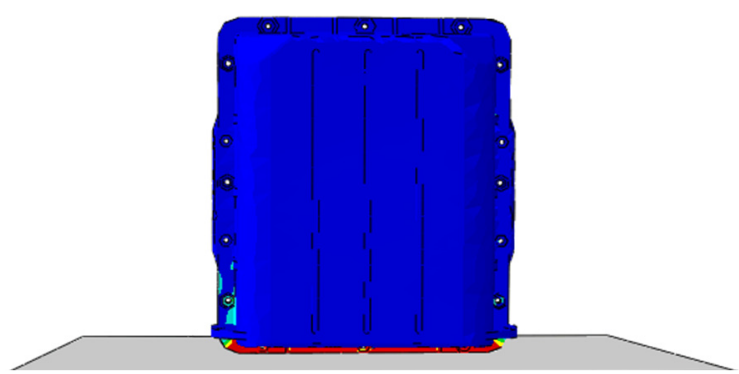

(b) $1.5 \mathrm{~m}$

Fig9. Stress cloud map of edge surface drop 


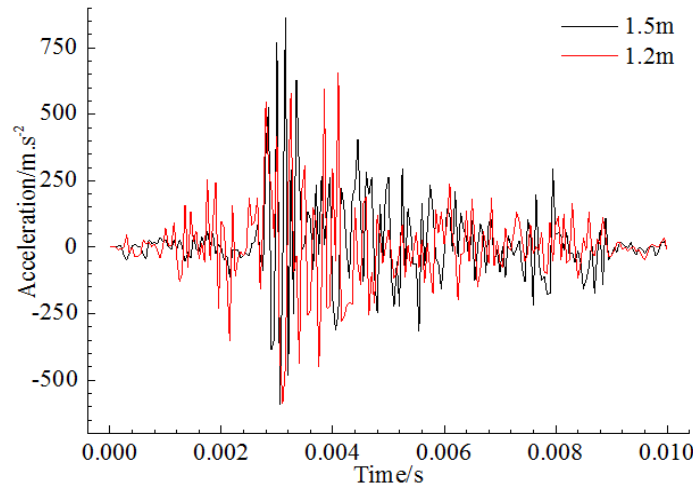

Fig10. Acceleration curve at the center of bottom

The stress cloud map of battery box after dropping was shown in Figure 9, it was found that there was obvious stress concentration on the bottom surface, the max Mises stress was bigger than bottom drop because of the small side area. Acceleration curve at the center of the bottom during drop was shown in Figure 10, it can be found that

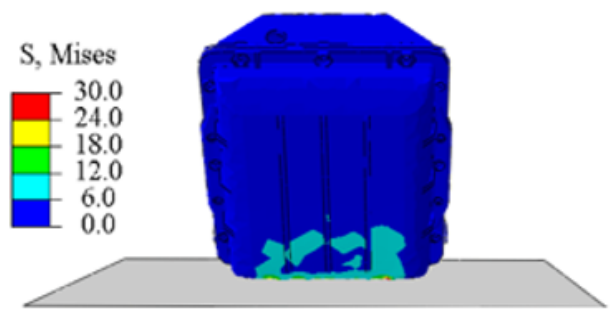

(a) $1.2 \mathrm{~m}$

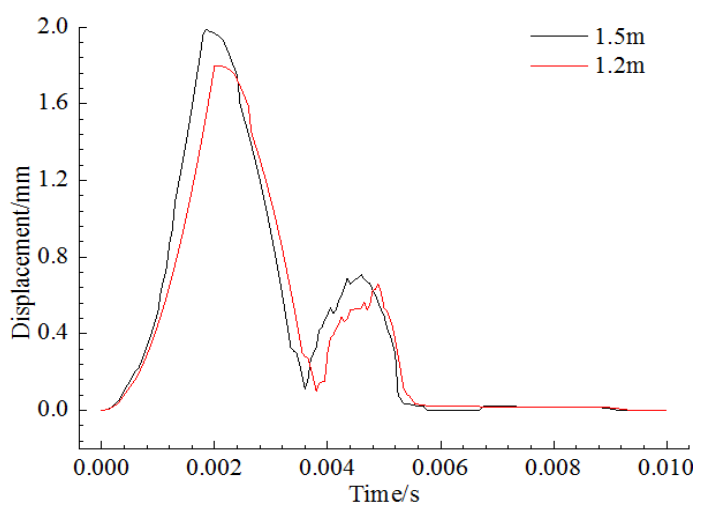

Fig11. Displacement curve at the center of bottom

the acceleration increased around $0.003 \mathrm{~s}$ and then decreased up and down around zero when the battery box hit the ground. Displacement curve at the center of the bottom surface during drop was shown in Figure 11, it can be found that the battery box bounced up and down after landing.

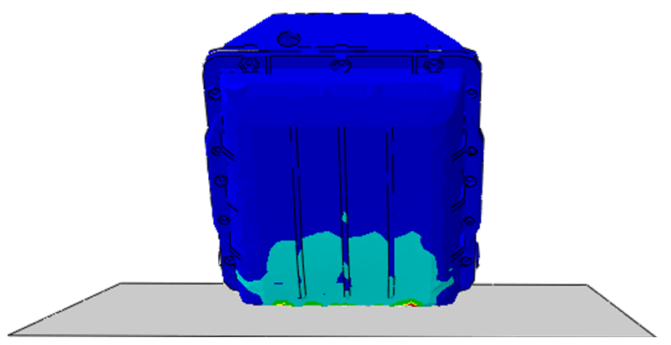

(b) $1.5 \mathrm{~m}$

Fig12. Figure 12. Side edge drop of battery box stress cloud map

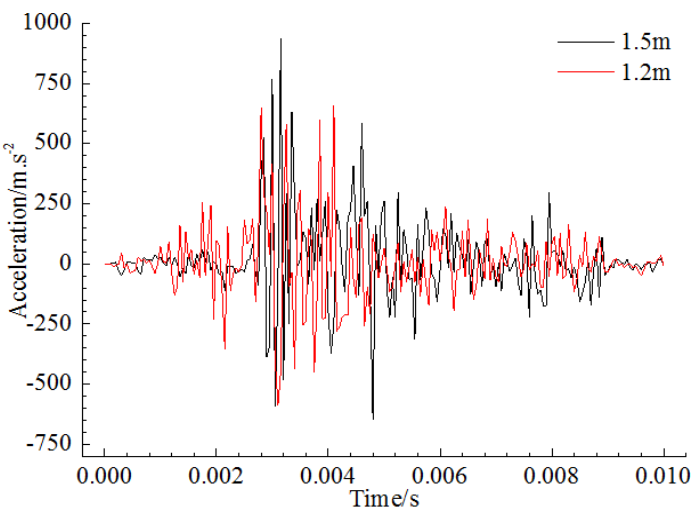

Fig13. Acceleration curve at the center of bottom

The edge drop cloud map was shown in Figure 12, it can be found that there remained obvious stress concentration, the max Mises stress was up to $79 \mathrm{MPa}$ when dropped from the height of $1.5 \mathrm{~m}$. the yield stress of battery box is $50 \mathrm{MPa}$, thus, the shell was yielded in a small range when battery box fall from the height of $1.5 \mathrm{~m}$. Acceleration curve at the center point of the bottom box during drop was shown in Figure 13, it can be found that

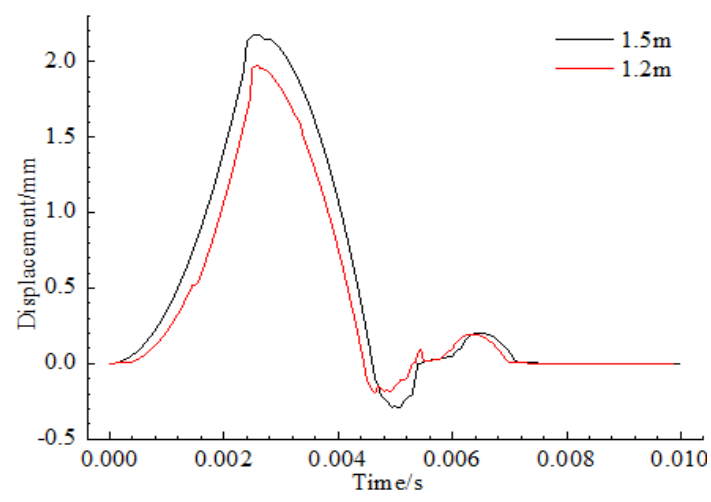

Fig14. Displacement curve at the center of bottom

acceleration began to increase sharply when the time close to $0.003 \mathrm{~s}$, then decreased gradually, and after $0.008 \mathrm{~s}$ tend to zero. Displacement curve at the center of bottom was shown in Figure 14, it can be found that the battery hit the ground, then quickly bounced off the ground for twice and finally landing, but the range was very small, and can be negligible. 


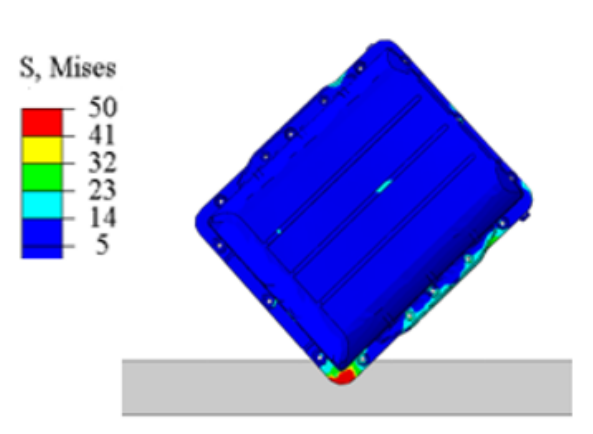

(a) $1.2 \mathrm{~m}$

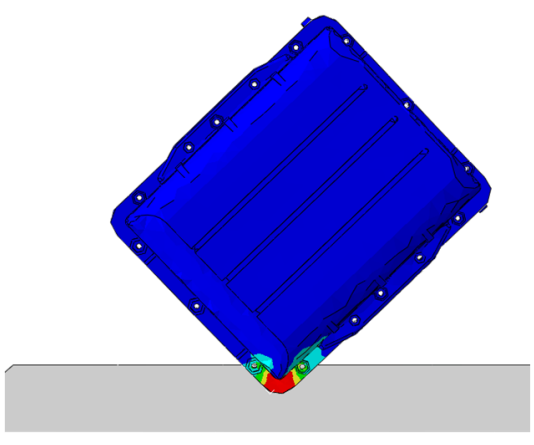

(b) $1.5 \mathrm{~m}$

Fig15. Corner drop of battery box stress cloud

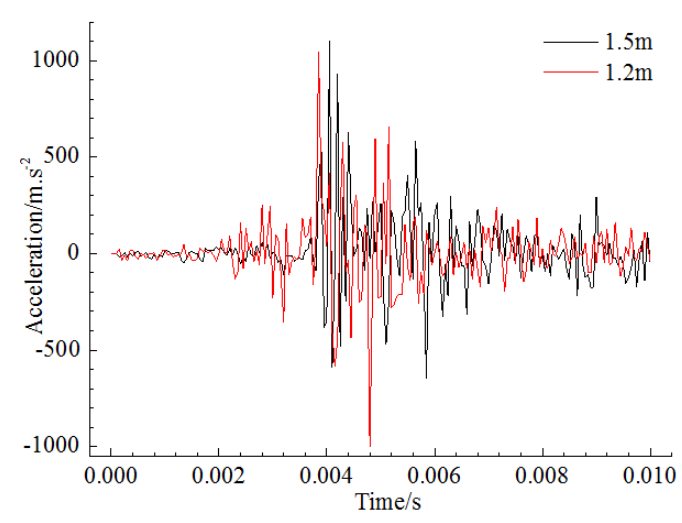

Fig16. Acceleration curve at the center of bottom

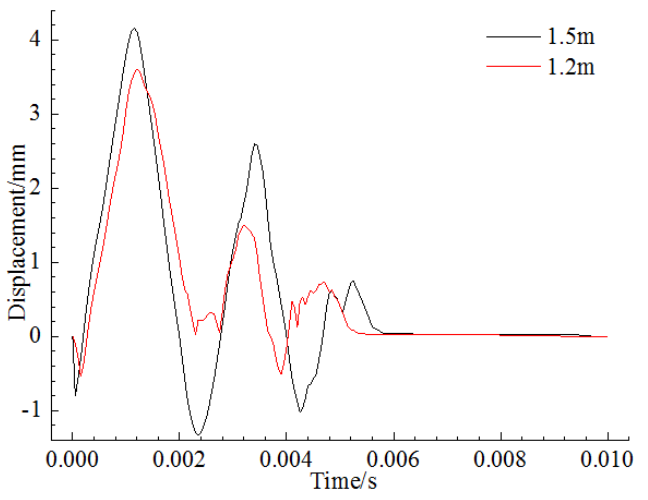

Fig17. Displacement curve at the center of bottom
The Mises stress cloud map was shown in Figure 15, it can be found that local stress concentration on the bottom corner, the max stress was up to $87 \mathrm{MPa}$ when fall from the height of $1.5 \mathrm{~m}$, the shell of battery box was yielded in a small range when the battery box hit the ground by its edge, because the yield stress of battery box is $50 \mathrm{MPa}$. Acceleration curve at the center point of the bottom box during drop was shown in Figure 16, it can be found that acceleration increases sharply around $0.004 \mathrm{~s}$, however, after $0.006 \mathrm{~s}$, it decreased and fluctuated to zero. Displacement curve at the center of the bottom was shown in Figure 17, it can be found that battery box bounced off the ground after hitting the ground, then fell and bounced twice, and finally landed.

\section{Conclusions}

1) The drop positions have great influence on force when the battery box fall freely, which the corner drop is the most dangerous force situation, and its shell will be yielded in a small range, the Mises stress of surface drop are less and safer, because the surface drop contact area is larger when hits the ground;

2) The force is also affected by the drop height when the battery box falls freely, the Mises stress which dropped from the height of $1.5 \mathrm{~m}$ is bigger than the height of $1.2 \mathrm{~m}$, and the bounced height is higher.

\section{References}

1. Li M S. China solar photovoltaic industry investment analysis and forecast report 2010-2015 (top, middle and bottom volumes) [J]. CIC Adviser, 2010 (6) :1718 .

2. Tannous S, Manneh R, Harajli H, et al. Comparative cradle-to-grave life cycle assessment of traditional grid-connected and solar stand-alone street light systems: a case study for rural areas in Lebanon[J]. Journal of Cleaner Production, 2018, 186 (10) : 963977.

3. Ricci R, Vitali D, Montelpare S. An innovative windsolar hybrid street light: Development and early testing of a prototype $[\mathrm{J}]$. International Journal of Low-Carbon Technologies, 2014, 10 (4) :101-106.

4. Xiao X S. Wireless sensor network in wind and solar hybrid street lamp application[C]. The 27th Chinese Control and Decision Conference. IEEE, 2015, 99104.

5. Bora S A, Pol P V. Development of solar street lamp with energy management algorithm for ensuring lighting throughout a complete night in all climatic conditions[C]. International Conference on Inventive Computation Technologies. IEEE, 2017,231-235.

6. Li Y X, Yang Q S, Tian Y J. Background Response Equivalent Static Wind Load of Large-Span Roofs 
Based on Energy Equation[J]. Applied Mechanics and Materials, 2011 (04) : 99-100.

7. Jian Y, You Y P, et al. Time-domain analysis for windinduced response of a dish solar thermal power generation system's frame structure[J]. Journal of Vibration \& Shock, 2016,35 (07) :177-185.

8. Bin L, Hao T W, Zhao Y G. Wind-induced response analysis and wind vibration control of a wind turbine tower drum[J]. Engineering Mechanics, 2017,34 (12) :134-138.

9. Bei C, Rong G L, Gui H X. Numerical simulation and test on wind-induced transient dynamic response of CFRP cable[J]. China Journal of Highway \& Transport, 2015,28 (1) :54-61.

10. Xie H L, Yin Z K, Wang T, et al. Analysis of Dynamic and Dynamic Structure Performance of Solar Lamp[J]. Mechanical and Electrical Engineering Technology, 2018, 047 (011) : 163-165.

11. Wang T. Analysis of Wind Resistance Performance of Solar Street Lamp System [D]. 2019. 